\title{
Left paraduodenal hernia: case report and review of the literature
}

\author{
Gavin A Falk, ${ }^{1}$ Basil J Yurcisin, ${ }^{2}$ Harry S Sell ${ }^{2}$ \\ ${ }^{1}$ Department of General Surgery, Cleveland Clinic Foundation, Cleveland, Ohio, USA \\ ${ }^{2}$ Department of Surgery, UPMC Mercy, Pittsburgh, Pennsylvania, USA \\ Correspondence to Gavin A Falk, gavfalk@rcsi.ie
}

\begin{abstract}
Summary
Paraduodenal hernias are congenital internal hernias that usually present with non-specific symptoms, and are therefore rarely diagnosed preoperatively. Left-sided paraduodenal hernias are three times more likely to occur than right-sided ones. Both hernias present similarly, but have a differing embryological basis. Here, the case of a 76-year-old woman with a left paraduodenal hernia presenting with small bowel obstruction is presented, and a brief discussion of the literature on its diagnosis and management given.
\end{abstract}

\section{BACKGROUND}

Our patient, a 76-year-old woman, presented with small bowel obstruction caused by a paraduodenal hernia. While this congenital anomaly is not very common, it should be included in the differential diagnosis of any patient with small bowel obstruction in the absence of previous abdominal surgery. Timely surgical intervention minimises the mortality and morbidity associated with the acute presentation of this hernia.

\section{CASE PRESENTATION}

A 76-year-old Caucasian woman presented from an outside hospital with a 1-day history of diffuse abdominal pain, worse suprapubically. The pain was described as sharp, constant, non-radiating and associated with nausea and an episode of postprandial non-bilious emesis. The patient had a bowel movement on the day prior to admission. Her previous medical history included diet-controlled type II diabetes mellitus and mild hypertension. A physical examination revealed a mass in her left upper quadrant.

\section{INVESTIGATIONS}

A CT scan was performed and loops of dilated small bowel consistent with obstruction were seen (figures 1 and 2).

\section{DIFFERENTIAL DIAGNOSIS}

Since this patient had no previous surgical history, a working diagnosis of an internal hernia was made.

\section{TREATMENT}

The patient was brought to the operating room for investigation of her small bowel obstruction. An exploratory laparotomy revealed an abnormal anatomy, with dilated loops of small bowel within a hernial sac in the left upper abdomen. The hernia appeared to protrude through the mesentery of the large bowel and incorporated a large segment of bowel from the duodenum to mid jejunum. A tight adhesive band close to the neck of the hernia sac along the mesentery of the small bowel was found and removed. Once this was performed, it became possible to reduce the contents of the hernia and the hernial sac was excised.

The bowel was run in its entirety and a small section of mid jejunum was found with transmural necrosis. This section of bowel was resected and an anastamosis created along the antimesenteric border with gastrointestinal anastomosis (GIA) and transverse anastomosis (TA) staplers. The mesenteric defect was then closed with a running Vicryl stitch. The omentum was draped over the small bowel and a piece of Seprafilm placed before closure. The abdomen was closed using two running polydioxone (PDS) sutures and the skin closed with staples. The patient's postoperative course was uneventful.

\section{DISCUSSION}

Internal hernias are an uncommon cause of intestinal obstruction, accounting for $0.2 \%$ to $0.9 \%$ of cases. ${ }^{1}$ An internal hernia is formed when a viscus protrudes through a mesenteric or peritoneal orifice within the peritoneal cavity. Paraduodenal hernias are the most common type of internal hernias, accounting for more than $50 \%$ of reported cases. ${ }^{1}$ Left-sided paraduodenal hernias are three times more common than right-sided paraduodenal hernias, and have a 3:1 male to female ratio. ${ }^{2}$

Left paraduodenal hernias are congenital anomalies formed during midgut rotation, when small bowel invaginates into an avascular segment of left mesocolon. The small bowel becomes entrapped between the mesocolon and the posterior abdominal wall, forming the anterior wall of the hernia sac. It has therefore been proposed that a more appropriate name for a paraduodenal hernia may be a congenital 'mesocolic' hernia. ${ }^{3}$ The space into which the bowel herniates is called Landzert's fossa, and is found behind the fourth part of the duodenum (figure 3). At autopsy Landzert's fossa has been found to be present in approximately $2 \%$ of the population. ${ }^{4-6}$ A left paraduodenal hernia usually contains most of the small bowel, from the fourth part of the duodenum to terminal ileum, and the colon usually 


\section{BMJ Case Reports}

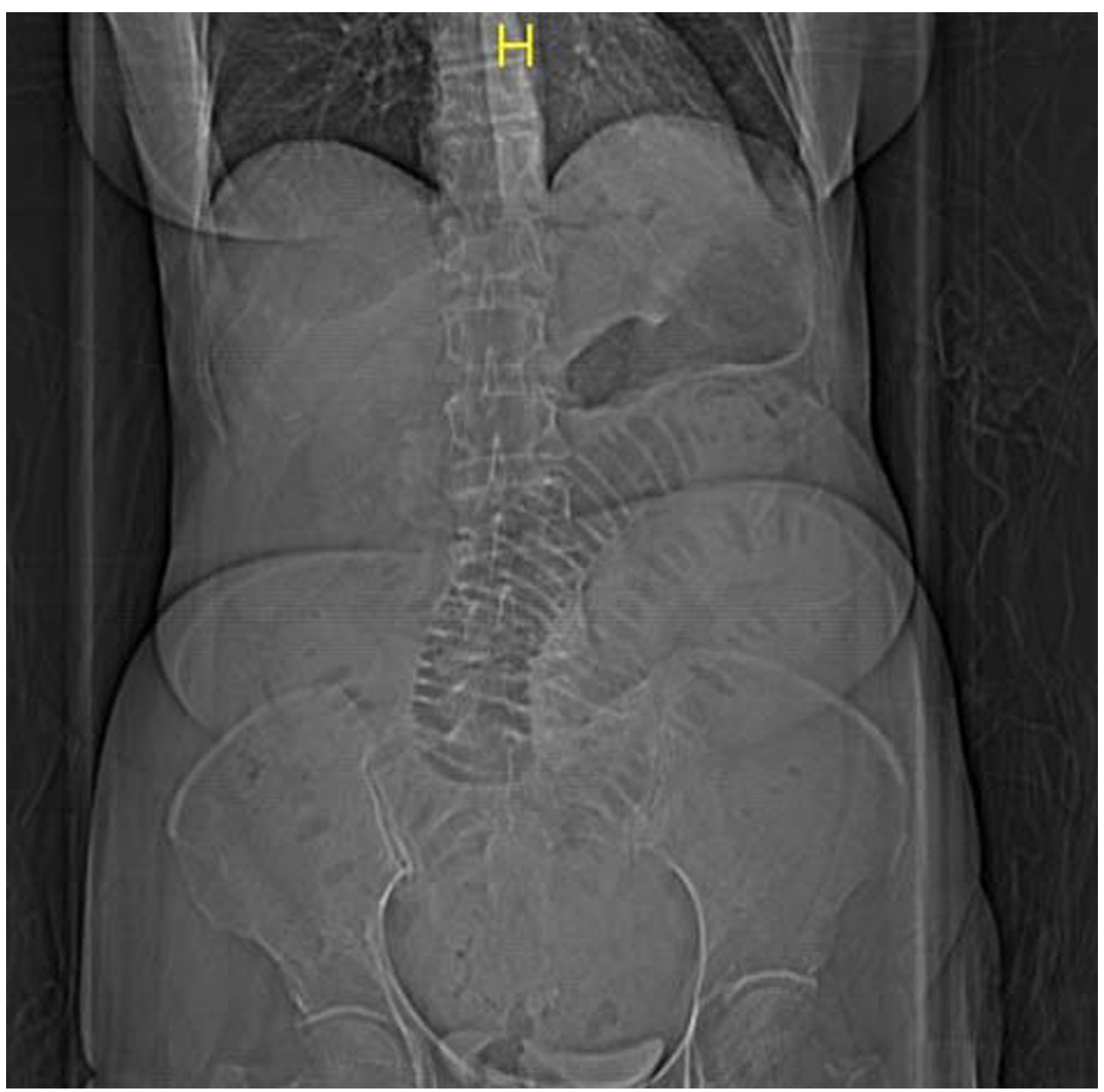

Figure 1 Scout film showing dilated loops of small bowel in left upper quadrant.

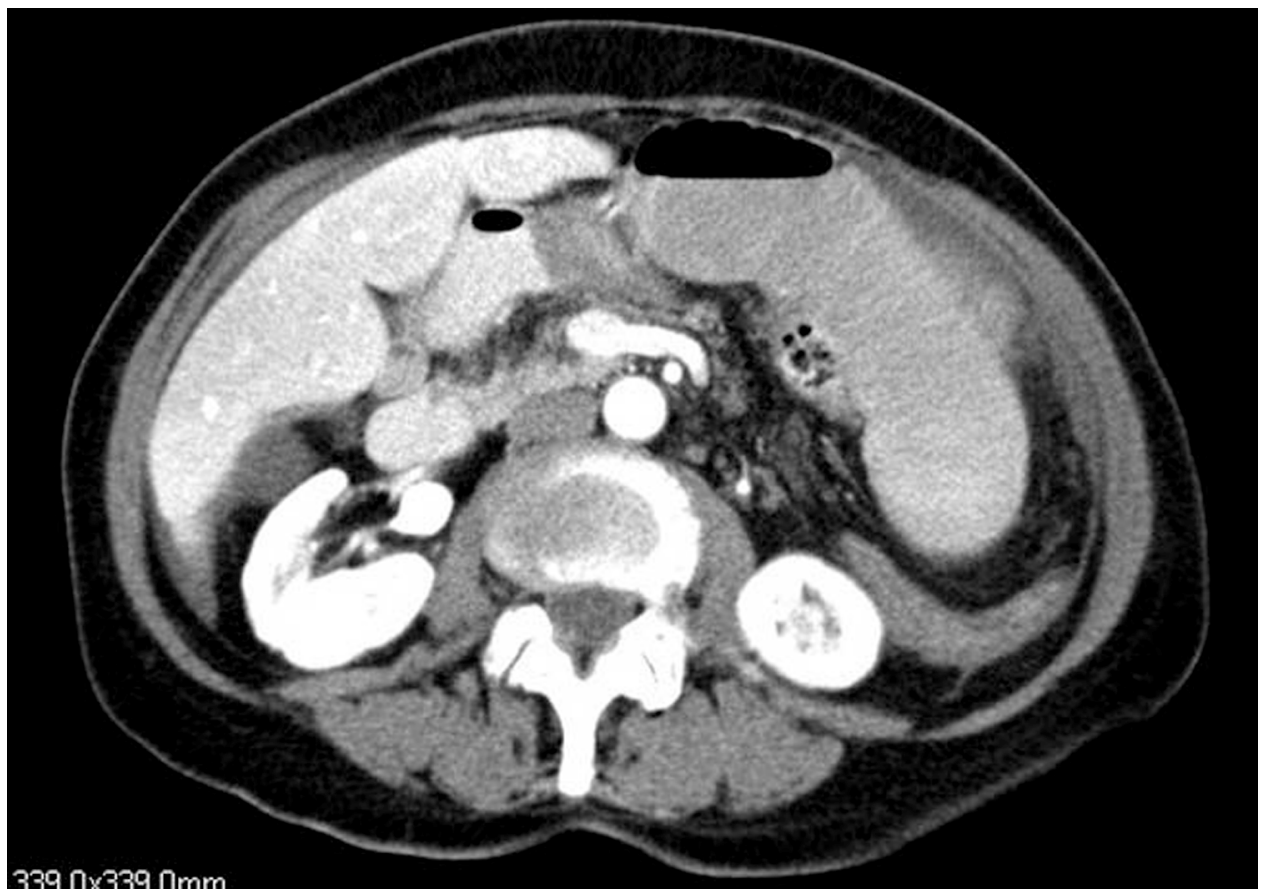

Figure 2 CT scan showing dilated loops of small bowel in left upper quadrant and the hernial neck (arrow). 


\section{BMJ Case Reports}

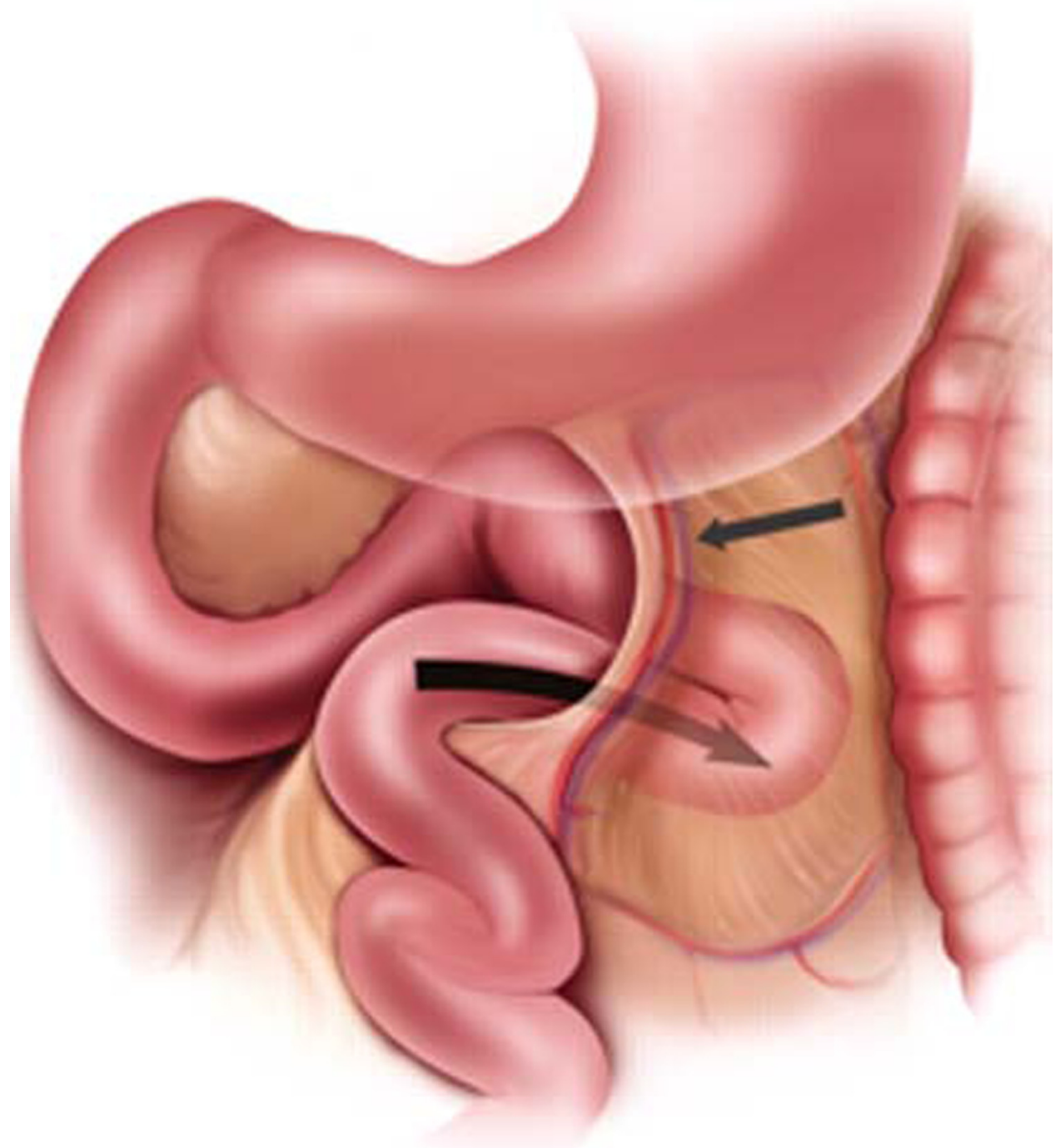

Figure 3 Illustration showing a loop of small bowel prolapsing (curved arrow) through Landzert's fossa, located behind the inferior mesenteric vein and left colic artery (straight arrow).

resides in its anatomically correct position. Occasionally the descending colon may be found to the right of the hernia, and there exists a risk of colonic volvulus especially if there is a long mesentery.

Right paraduodenal hernias are also congenital in origin, and arise when bowel herniates through a defect in the first part of the jejunal mesentery called Waldeyer's fossa (figure 4). Waldeyer's fossa is found in $1 \%$ of the population at autopsy. ${ }^{1}$ The hernia is found in the right side of the transverse mesocolon and extends inferolaterally behind the ascending mesocolon. Right-sided paraduodenal hernias are usually larger and more fixed than in left-sided paraduodenal hernias, ${ }^{7}$ and are associated with small bowel non-rotation.

CT is the imaging modality of choice in diagnosing a paraduodenal hernia. A CT scan of a left paraduodenal hernia usually demonstrates clustering of loops of small bowel at or above the ligament of Treitz or behind the stomach, causing a mass effect on the posterior wall. ${ }^{568}$ Sometimes, inferior displacement of the transverse colon can be seen, as well as inferior mesenteric vessel abnormalities. ${ }^{568}$ If small bowel obstruction is not present, the collapsed bowel loops may be mistaken for a soft tissue mass. A high index of suspicion for this condition can help avoid unnecessary and unsuitable invasive procedures such as CT-guided biopsy. ${ }^{9}$ A helpful study would be an upper gastrointestinal series with small bowel follow through, which reveals contrastfilled bowel loops in the left upper quadrant.

A CT scan of a right-sided paraduodenal hernia reveals a cluster of small bowel loops on the right side of the abdomen, usually just below the third part of the duodenum. As the afferent and efferent loops of bowel are involved in the hernia, they may appear narrowed and decompressed. Sometimes the small bowel can be seen looping around the superior mesenteric vessels at the root of the small-bowel mesentery.

Paraduodenal hernias usually present with symptoms of acute small bowel obstruction such as nausea, vomiting, abdominal pain and distension, on a background of recurrent vague abdominal pain. Sometimes, as in our case, clustering of dilated loops of small bowel may be palpable. Patients with a left paraduodenal hernia usually present 


\section{BMJ Case Reports}

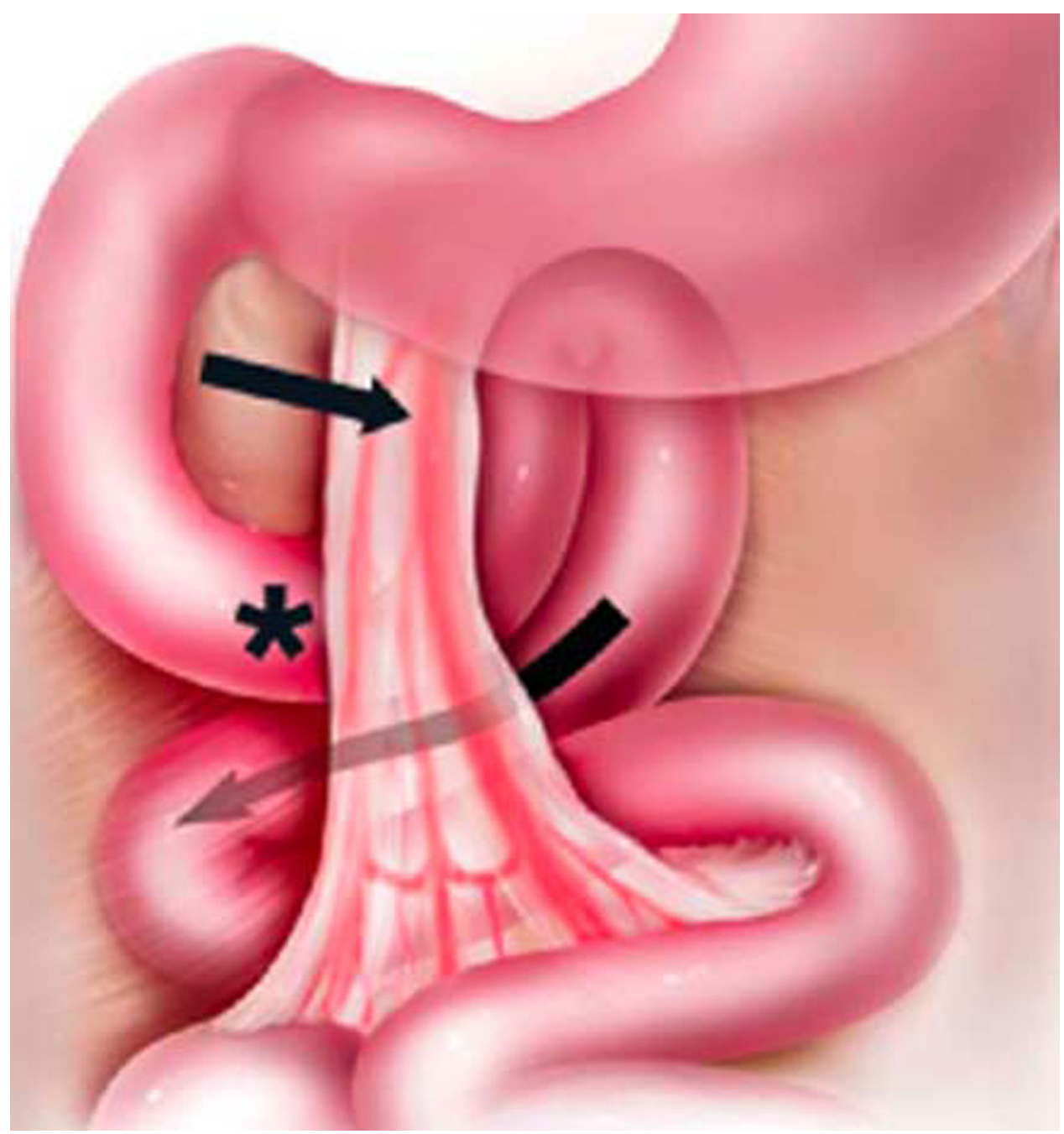

Figure 4 Illustration showing a right paraduodenal hernia with a loop of small bowel prolapsing (curved arrow) through Waldeyer's fossa, behind the superior mesenteric artery (SMA) (straight arrow) and inferior to third part of the duodenum (asterisk).

during the fourth to sixth decade of life, and the mean age of presentation is 38.5 years. $^{2}$ Our patient is unusual in that she presented at an advanced age of 76 , without prior history of abdominal pain or other gastrointestinal symptoms.

The surgical approach to a paraduodenal hernia is the same as that of any hernia, that is reduce the hernia, restore the normal anatomy and repair the defect. Timely surgical intervention is important due to the very high (50\%) lifetime probability of incarceration or strangulation. ${ }^{510}$ With a left-sided hernia, care must be taken not to damage the left colic artery or inferior mesenteric vessels, which are often found anterior to the hernia opening. Similarly, care must be taken not to damage the superior mesenteric vessels in the repair of a right-sided hernia. While an open operation is the usual approach to this condition, successful laparoscopic repair of the right ${ }^{11}$ and left ${ }^{12}{ }^{13}$ paraduodenal hernias have been reported in the literature. A recent small case series comparing laparoscopic to open repair of paraduodenal hernias showed that the laparoscopic approach resulted in a shorter hospital stay, earlier intake of soft diet and a lower rate of postoperative ileus. ${ }^{13}$

\section{Learning points}

- Internal hernias are an uncommon cause of intestinal obstruction, accounting for $0.2 \%$ to $0.9 \%$ of cases. An internal hernia is formed when a viscus protrudes through a mesenteric or peritoneal orifice within the peritoneal cavity.

- Paraduodenal hernias are the most common type of internal hernias, accounting for more than $50 \%$ of reported cases.

- Paraduodenal hernias usually present with symptoms of acute small bowel obstruction such as nausea, vomiting, abdominal pain and distension with a background of recurrent vague abdominal pain.

- Paraduodenal hernias should be included in the differential diagnosis of any patient with a diagnosis of small bowel obstruction in the absence of previous abdominal surgery.

- Timely surgical intervention should be undertaken to minimise the mortality and morbidity associated with the acute presentation of a paraduodenal hernia. 


\section{BMJ Case Reports}

Competing interests None.

\section{Patient consent Obtained.}

\section{REFERENCES}

1. Selùuk D, Kantarci F, Ogüt G, et al. Radiological evaluation of internal abdominal hernias. Turk J Gastroenterol 2005;16:57-64.

2. Khan MA, Lo AY, Vande Maele DM. Paraduodenal hernia. Am Surg 1998;64:1218-22.

3. Willwerth BM, Zollinger RM Jr, Izant RJ Jr. Congenital mesocolic (paraduodenal) hernia. Embryologic basis of repair. Am J Surg 1974; 128:358-61.

4. Blachar A, Federle MP. Internal hernia: an increasingly common cause of small bowel obstruction. Semin Ultrasound CT MR 2002;23:174-83.

5. Blachar A, Federle MP, Dodson SF. Internal hernia: clinical and imaging findings in 17 patients with emphasis on CT criteria. Radiology 2001:218:68-74.
6. Osadchy A, Weisenberg N, Wiener Y, et al. Small bowel obstruction related to left-side paraduodenal hernia: CT findings. Abdom Imaging 2005;30:53-5.

7. Martin LC, Merkle EM, Thompson WM. Review of internal hernias: radiographic and clinical findings. AJR Am J Roentgenol 2006;186:703-17.

8. Warshauer DM, Mauro MA. CT diagnosis of paraduodenal hernia. Gastrointest Radiol 1992;17:13-15.

9. Huang YM, Chou AS, Wu YK, et al. Left paraduodenal hernia presenting as recurrent small bowel obstruction. World J Gastroenterol 2005;11:6557-9.

10. Davis R. Surgery of left paraduodenal hernia. Am J Surg 1975:129:570-3.

11. Antedomenico E, Singh NN, Zagorski SM, et al. Laparoscopic repair of a right paraduodenal hernia. Surg Endosc 2004;18:165-6.

12. Uematsu T, Kitamura $\mathrm{H}$, Iwase $\mathrm{M}$, et al. Laparoscopic repair of a paraduodenal hernia. Surg Endosc 1998;12:50-2.

13. Jeong GA, Cho GS, Kim HC, et al. Laparoscopic repair of paraduodenal hernia: comparison with conventional open repair. Surg Laparosc Endosc Percutan Tech 2008;18:611-15.

\footnotetext{
This pdf has been created automatically from the final edited text and images.

Copyright 2010 BMJ Publishing Group. All rights reserved. For permission to reuse any of this content visit

http://group.bmj.com/group/rights-licensing/permissions.

BMJ Case Report Fellows may re-use this article for personal use and teaching without any further permission.

Please cite this article as follows (you will need to access the article online to obtain the date of publication).

Falk GA, Yurcisin BJ, Sell HS. Left paraduodenal hernia: case report and review of the literature. BMJ Case Reports 2010;10.1136/bcr.04.2010.2936, date of publication

Become a Fellow of BMJ Case Reports today and you can:

Submit as many cases as you like

- Enjoy fast sympathetic peer review and rapid publication of accepted articles

- Access all the published articles

- Re-use any of the published material for personal use and teaching without further permission

For information on Institutional Fellowships contact consortiasales@bmjgroup.com

Visit casereports.bmj.com for more articles like this and to become a Fellow
} 